Er:YAG lazer ya da geleneksel yöntem ile

hazırlanmış sınıf $\mathrm{V}$

kavitelerde akışkan

kompozitlerin kenar

uyumlarının araştırılması

\section{Assessment of the marginal microleakage of flowable composites in class $V$ cavities prepared by Er:YAG laser and high-speed bur}

\section{Dr. Öğr. Üyesi Nilüfer ÜSTÜN}

İstanbul Medipol Üniversitesi, Diş Hekimliği Fakültesi, Çocuk Diş Hekimliği AD, İstanbul

Orcid ID: 0000-0001-5489-6883

Doç. Dr. Yeliz GÜVEN

İstanbul Üniversitesi, Diş Hekimliği Fakültesi,

Pedodonti AD, İstanbul

Orcid ID: 0000-0002-4637-6025

Dr. Öğr. Üyesi Asiye Nur DiNÇER

Bezmialem Vakıf Üniversitesi, Diş Hekimliği Fakültesi,

Endodonti $A D$, İstanbul

Orcid ID: 0000-0002-6713-1940

Prof. Dr. Elif Bahar TUNA INCE

İstanbul Üniversitesi, Diş Hekimliği Fakültesi,

Pedodonti AD, İstanbul

Orcid ID: 0000-0001-6450-6869

Prof. Dr. Emre ÖZEL

Kocaeli Üniversitesi Diş Hekimliği Fakültesi،

Restoratif Diş Tedavisi AD, Kocaeli

Orcid ID: 0000-0003-1883-5172

Geliș tarihi: 7 Nisan 2020

Kabul tarihi: 14 Ağustos 2020

doi: 10.5505/yeditepe.2021.50469

Yazışma adresi:

Doç. Dr. Yeliz Güven

İstanbul Üniversitesi, Diş Hekimliği Fakültesi,

Pedodonti $A D$, İstanbul

Prof. Dr. Cavit Orhan Tütengil Sokak.No.4

Vezneciler-Fatih-ISTANBUL

Tel: 05359663894

E-posta:yguven@istanbul.edu.tr
ÖZET

Amaç: Bu çalışmanın amacı, Er:YAG lazer ya da yüksek hızlı döner aletler ile kavite hazırlığı yapılan ve üç farklı akışkan kompozit materyali kullanılarak gerçekleştirilen sınıf $\mathrm{V}$ restorasyonlarda kenar mikrosızıntılarının incelenmesidir.

Gereç ve Yöntem: Bu in-vitro çalışmada, toplam 33 adet üçüncü büyük azı dişlerinin bukkal ve lingual yüzeylerinde Er:YAG lazer ya da frez kullanılarak sınıf $\mathrm{V}$ kaviteler hazırlanan örnekler altı gruba $(n=11)$ ayrıldı ve üretici firmanın talimatlarına uygun olarak üç farklı akışkan kompozit ile restore edildi. Grup 1: Lazer ile hazırlık (Ih)+Estelite Flow Quick High flow (EF); Grup 2: Ih+G-aenial Flo (GF); Grup 3: Ip+Herculite XRV Ultra Akış (HF); Grup 4: Frez ile hazırlık (fh)+EF; Grup 5: fh+GF; Grup 6: fh+HF. Isısal çevrim uygulanmasının ardından örnekler \%0,5 metilen mavisi solüsyonunda 24 saat süresince bekletildi. Boya penetrasyonu sonucu oluşan mikrosızıntı, stereomikroskop altında x40 büyütme ile incelendi. Verilerin analizinde Kruskal Wallis ve Mann-Whitney U testleri kullanıldı $(p<0,05)$.

Bulgular: Grup 3'te oluşan mikrosızıntı düzeyi grup 2'ye göre istatistiksel açıdan anlamlı derecede düşük bulunurken (p:0,042), diğer gruplar arasındaki mikrosızıntı düzeylerinde anlamlı bir farklılık saptanmadı. Gruplardaki gingival ve oklüzal yüzeyler karşılaştırıldığında mikrosızıntı düzeyleri arasında istatistiksel olarak anlamlı bir farklılık bulunmadı $(p<0,05)$.

Sonuç: Sınıf V kavite hazırığında yüksek hızlı döner alet ya da Er:YAG lazer uygulaması ve bu kavitelerin restorasyonlarında farklı akışkan kompozit materyallerinin kullanılması, oklüzal ve gingival kenarlarda oluşan mikrosızıntı düzeyini etkilememektedir.

Anahtar kelimeler: Mikrosızıntı, Er:YAG lazer, Yüksek hızlı döner alet, Kavite hazırlığı, Akışkan kompozitler.

\section{SUMMARY}

Aim: The aim of this study was to examine the Er:YAG laser and high-speed bur cavity preparation on the marginal microleakage of class $\mathrm{V}$ cavities restored with three different flowable composites.

Materials and Methods: This in-vitro study was conducted on class $V$ cavities prepared on buccal and lingual surfaces of 33 third molar teeth in six groups ( $n=11$ ) of Er:YAG laser and bur preparation. The cavities were restored with three different flowable composites according to the manufacturer's instructions. Group 1: Laser preparation (lp)+Estelite Flow Quick High flow (EF); Group 2: Ip+G-aenial Flo (GF); Group 3: Ip+Herculite XRV Ultra Flow (HF); Group 4: Bur preparation (bp)+EF; Group 5: bp+GF; Group 6: bp+HF. After thermocycling, the teeth were immersed in $0.5 \%$ methylene blue dye for 24 hours. The teeth were examined under a stereomicroscope at $\times 40$ magnification to detect the microleakage. Data were analyzed by Kruskal-Wallis and Mann Whitney U tests $(p<0.05)$.

Results: While the microleakage in group 3 was found significantly lower than group 2 (p:0.042), there was no significant difference among the other groups $(p>0.05)$. In terms of gin- 
gival and occlusal surfaces, no statistically significant difference in microleakage was observed among all groups ( $p>0.05$ ).

Conclusion: Class $V$ cavity preparations with high-speed bur and Er:YAG laser, and the use of different flowable composites did not influence the microleakage at the gingival or occlusal margins.

Keywords: Microleakage, Er:YAG laser, High-speed bur, Cavity preparation, Flowable composites.

\section{GíRiş}

Günümüzde kavite hazırlığı aşamasında sıklıkla tercih edilen ve geleneksel yöntem olarak kabul edilen döner alet kullanımının istenenden fazla diş dokusu kaybı, ıSı, ses, titreşim ve mikroçatlak oluşumu gibi dezavantajlara sahip olduğu belirtilmektedir.' Bu olumsuzlukların giderilmesi amacıyla düşük hızlıdan ultra yüksek hızlıya kadar değişen çeşitli ekipmanların dahil olduğu farklı döner alet sistemleri geliştirilmiştir. Ancak kavite hazırlığında döner alet kullanımına ilişkin temel sorunun pulpa üzerinde ağrılı uyaran oluşturan baskı ve termal etki olduğu bildirilmiştir.? Bunun üzerine araştırmacılar açığa çıkan ısıyı, titreşimi ve bunun neden olduğu ağrıyı en aza indirgemek için birçok alternatif minimal invaziv kavite hazırlığı yöntemini incelemişlerdir. Elde edilen bulgulara göre ise sert doku lazerlerinin kavite hazırlığında kullanımının, tedavi sırasında daha az titreşim ve baskı oluşturarak lokal anestezi intiyacını anlamlı oranda azaltması nedeniyle restoratif diş hekimliğinde tercih edilebilir olduğu belirtilmiştir.2,3

Diş hekimliğinde, sert doku uygulamalarında en etkili lazerler olduğu belirtilen erbium: yittriyum-aluminyum-garnet (Er:YAG; dalga boyu: 2,94 $\mu \mathrm{m}$ ) ve erbiyum, krom: yittriyum-selenyum-galyum-garnet (Er,Cr:YSGG; dalga boyu: 2,78 $\mu \mathrm{m}$ ) olmak üzere 2 tip lazer kullanılmaktadır. ${ }^{4,5} \mathrm{Er}: Y A G$ lazerlerin diğer lazerlere kıyasla su molekülleri tarafından emiliminin en fazla olduğu ve hidroksiapatitlere afinitelerinin oldukça yüksek olduğu bildirilmektedir. ${ }^{6}$ Bu lazerlerin kavite hazırlığında kullanımının, hem uygulama sırasında hasta konforunu azaltan titreşim ve basınç oluşumunun önlenmesi, hem de enfekte diş sert dokularının etkili ve hassas bir şekilde ablasyonuna olanak tanıması sayesinde geleneksel yöntemlere göre oldukça avantajlı oldukları vurgulanmaktadır. ${ }^{7,8}$ Tüm adeziv sistemler başlangıçta, geleneksel yöntemlerle hazırlanan kavitelere uygulanmak amacıyla geliştirildiğinden; kavite hazırlığı sırasında lazerlerin kullanımı ile diş dokularında meydana gelen mekanik ve kimyasal değişimler, bu adeziv sistemlerin retansiyonuna etkisinin araştırımasına yönelik intiyacı artırmıştır. ${ }^{9} \mathrm{Bu}$ nedenle konuyla ilgili yapılan çalışmalarda, kavite hazırlığı aşamasında lazer uygulamasının diş dokularında meydana getirdiği yüzeysel değişikliklerin geleneksel yöntemlere kıyasla mikrosızıntı miktarını nasıl etkilediğinin değerlendirilmesinin, üzerinde durulması gereken temel noktalardan biri olduğu belirtilmiştir.7

Sınıf V lezyonlar, diş eti kenarında sonlanmaları nedeniyle kavite sınırlarında daha az miktarda sağlam mine dokusu bulundurmaktadır. Bu durum ise servikal restorasyonlarda kullanılan kompozit materyallerinin, polimerizasyon büzülmesini ve ağız ortamındaki ısı değişimleri ile çiğneme kuvvetlerine olan dayanımını olumsuz etkilemektedir. Servikal lezyonların kompozit materyallerle ideal bir şekilde restore edilemedikleri durumlarda kavite duvarı ve uygulanan restoratif materyal arasında mikro boşlukların oluştuğu, bu mikro boşlukların ise kenar mikrosızıntılarına yol açtığı belirtilmektedir. Bakterilerin, ağız sıvılarının, iyon ya da moleküllerin bu mikro-boşluklardan geçmeleri sonucu meydana gelen mikrosızıntının restorasyon kenarlarında renklenmelere, diş-restorasyon ara yüzeyinde sekonder çürük oluşumuna, restore edilmiş dişte hassasiyet gelişimine ve pulpa patolojilerinin gözlenmesine neden olduğu bildirilmiştir. ${ }^{10}$ Rezin esaslı restoratif materyallerin yetersiz adezyonuna bağlı oluşan mikrosızıntının azaltılması ile dental restorasyonların başarısının önemli ölçüde arttığı ifade edilmiştir. ${ }^{3}$

1990 'ı yılların sonlarına doğru kullanımı yaygınlaşan akışkan kompozit materyallerin, geleneksel rezin esaslı kompozitlere göre daha az doldurucu madde içerdikleri ve daha düşük elastisite modülü ile viskoziteye sahip oldukları belirtilmiştir. ${ }^{11}$ Bu sayede akışkan kompozitlerin diş yüzeylerine kolayca adaptasyon sağlayarak, daha az sızıntı ve postoperatif hassasiyet özelliği göstermeleri nedeniyle izolasyon ve erişimin zor olduğu bölgelerde kullanımlarının avantajlı olduğu bildirilmiştir. ${ }^{12}$ Akışkan kompozitlerin, sınıf I ve sınıf II kavitelerin kompozit rezinler ile restorasyonundan önce alta ince bir tabaka şeklinde uygulanmasının restorasyonun ömrünü arttıracağı ve çok büyük olmayan Sınıf V kavitelerde ise daimi restorasyon materyali olarak kullanılabileceği belirtilmiştir. ${ }^{13}$ Ancak yapılan çalışmalar incelendiğinde akışkan kompozitlerin mikrosızıntıyı azaltma kapasitelerine ilişkin çelişkili sonuçlar olduğu gözlenmektedir. ${ }^{10}$ Bu nedenle, sınıf $\mathrm{V}$ lezyonların akışkan kompozitlerle restorasyonları sonucu oluşan mikrosızıntının değerlendirilmesine yönelik daha fazla sayıda çalışmaya intiyaç bulunmaktadır.

Bu çalışmanın amacı, Er:YAG lazer ya da geleneksel yöntem olan yüksek hızlı döner aletler ile kavite hazırıı̆ı yapılan ve üç farkıı akışkan kompozit materyali kullanılarak gerçekleştirilen sınıf $\mathrm{V}$ restorasyonlarda kenar mikrosızıntılarının karşılaştırılmasıdır.

\section{GEREÇ VE YÖNTEM}

Araştırmanın etik kurul onayı Kocaeli Üniversitesi Girişimsel Olmayan Klinik Araştırmalar Etik Kurulu'nun KÜ GOKAEK 2019/177 sayılı kararı ile alındı. Çalışmada, yaşları 20-40 arasında değişen gönüllü bireylerden çekilmiş çürüksüz ve restorasyonsuz, toplam 33 adet üçüncü büyük 
azı dişi kullanıldı. Gönüllü bireylerin, diş çekimi öncesinde çalışma hakkında bilgilendirilmesi ve aydınlatılmış onam formunu okuyup imzalamalarının ardından çekilen dişler düşük hızda döner alete (L-Motor 181 DBN INTRAmatic ve DURAtec 2068 D, KaVo Dental GmbH, Bismarckring, Almanya) takılan fırça (Stoddard Manufacturing Co. Ltd., Hertfordshire, Ingiltere) ile pomzalanarak (BIMS powder, Yüceller Diş Deposu, Türkiye) doku artıkları uzaklaştırıldı. Temizlenen dişler, dental loupe (Keeler Ltd, Windsor, Berkshire, İngiltere) yardımıyla 2,5X büyütmede minede olası bir çatlak varlığı yönünden incelendi. Herhangi bir çatlak gözlenmeyen dişler en fazla altı ay olmak koşuluyla deney gününe kadar buzdolabında $\left(4^{\circ} \mathrm{C}\right)$ distile su içerisinde saklandı ve distile su her on günde bir yenilendi. Er:YAG lazer (Fotona Lightwalker AT, Ljubljana, Slovenya) ya da frez ile hazırlanmış ve 3 farklı akışkan kompozit uygulanmış yüzeylerde restorasyonların mikrosızıntı ölçümlerinin değerlendirilebilmesi için toplam 6 grup $(n=11)$ oluşturuldu.

Grup 1: Er:YAG lazer ile hazırlık + Estelite Flow Quick High flow (Tokuyama Dental Corp, Japonya);

Grup 2: Er:YAG lazer ile hazırlık + G-aenial Flo (GC Corp, Japonya);

Grup 3: Er:YAG lazer ile hazırlık + Herculite XRV Ultra Flow (Kerr Corp, ABD);

Grup 4: Frez ile hazırlık + Estelite Flow Quick High flow;

Grup 5: Frez ile hazırlık+ G-aenial Flo;

Grup 6: Frez ile hazırlık+ Herculite XRV Ultra Flow.

Er:YAG lazer ve frez kullanılarak, örnek dişlerin bukkal ve lingual yüzeylerinin her birinde birer kavite olmak üzere toplam 66 adet Sınıf V kavite hazırlandı. Kaviteler oklüzal sınırları minede, servikal sınırları ise mine-sement sınırının $1 \mathrm{~mm}$ apikalinde olacak şekilde açıldı. Kavite boyutları için standart bir şablon kullanıldı. Böylece mesiodistal genişliği $4 \mathrm{~mm}$ ve oklüzogingival boyutu $3 \mathrm{~mm}$ olan, işaretli periodontal sonda yardımıyla derinlik kontrolü yapılarak 1,5 $\mathrm{mm}$ kavite derinliğine sahip standart kaviteler hazırlandı. Er:YAG lazer ile kavite hazırlığı nonkontakt başlık kullanılarak, diş yüzeyinden $10 \mathrm{~mm}$ uzakta olacak şekilde ve hava-su soğutması altında gerçekleştirildi. $100 \mu \mathrm{s}$ atım aralığında (MSP mod) çalışılan cihazda enerji değerleri üretici firmanın önerileri doğrultusunda $150 \mathrm{~mJ} / 20 \mathrm{~Hz}$ olarak belirlendi. Frez ile kavite hazırlığı sırasında ise hava-su soğutması altında elmas tersine konik (\#12) ve elmas fissür (\#10) frezler (Strauss \& Co., Industrial Diamonds Ltd. Ra'anana, İsrail) kullanıldı. Mine kenarları bizote edildi ve elmas frezler her 5 kavitede bir yenilendi. Hazırlanan kavitelerin mine yüzeylerine 20 sn \%35'lik ortofosforik asit (Scotchbond, 3M ESPE, St. Paul. MN, ABD) uygulanmasının ardından yüzeyler 10 sn yıkandı ve 5 sn kurutuldu. Hazırlanan diş yüzeylerine 15 sn boyunca 3M Single Bond Universal adeziv (3M ESPE, St. Paul. MN, ABD) uygulandı, 5 sn düşük basınçlı hava verilerek adeziv inceltildi ve ışık cihazı
(3M ESPE, St. Paul. MN, ABD) ile 10 sn boyunca polimerizasyon sağlandı. Ardından akışkan kompozit materyalleri üretici firmanın talimatlarına göre yüzeylere uygulanarak 20 sn ışıkla polimerize edildi. Restorasyonları tamamlanan dişler 24 saat distile suda bekletildikten sonra $13 \mathrm{~mm}$ çaplı Sof-Lex XT (3M ESPE, St. Paul. MN, ABD) diskler ile bitirme ve cilalama işlemleri gerçekleştirildi. Ardından tüm örneklere $5 \pm 2^{\circ} \mathrm{C}-55 \pm 2^{\circ} \mathrm{C}$ arasında, 500 defa yaşlandırma işlemi (Sd. Mechatronic Thermocycler Seelback, Almanya) uygulandı. Su banyolarında bekleme süresi 30 sn ve banyolar arası transfer süresi 3 sn olacak şekilde işlem tamamlandı.

Mikrosızıntı miktarlarının değerlendirilmesi için boya penetrasyon yöntemi kullanıldı. Boya penetrasyon testi öncesi boya geçişini engellemek için restorasyonların çevresindeki 1 mm'lik alan dışında kalan yerler önce iki kat şeffaf tırnak cilası ile, cilanın kurumasından sonra da boxing mumu ile kaplandı. Ardından örnekler etüvde $37^{\circ} \mathrm{C}^{\prime}$ de (ışık geçirmeyen bir ortamda), \%0, $5^{\prime}$ lik tamponlanmış metilen mavisi solüsyonu (Blueject, Vulcan Laboratories, Hindistan) içerisinde 24 saat süre ile bekletildi. Bu sürenin sonunda örnekler solüsyondan çıkarıldı ve musluk suyu altında mum artıkları temizlenerek tüm yüzeyler fırçalandı. Daha sonra örnekler su soğutmalı, düşük hızlı bir elmas kesme diski yardımıyla bukkalden linguale olacak şekilde uzunlamasına ikiye bölündü. Kesit alınan dişler stereomikroskop altında (SMZ 1000, Nikon Corporation, Tokyo, Japonya, 40X büyütmeli) iki farklı denetleyici tarafından gözlemlendi. Tüm restorasyonların gingival ve oklüzal yüzeyleri birbirinden bağımsız olarak skorlandı ve her incelenen bölüm için en yüksek penetrasyon derecesi belirlendi. Restorasyon kenarında oluşan mikrosızıntının değerlendirilmesinde standart bir puanlama sistemi kullanıldı (Tablo 1). ${ }^{14}$

Tablo 1. Kenar mikrosızıntısının değerlendirilmesinde kullanılan puanlama sistemi. ${ }^{14}$

\begin{tabular}{|c|c|c|c|c|c|}
\hline $\begin{array}{c}\text { Boya } \\
\text { penetrasyon } \\
\text { skoru }\end{array}$ & 0 & 1 & 2 & 3 & 4 \\
\hline $\begin{array}{l}\text { Othüzal } \\
\text { kenar }\end{array}$ & $\begin{array}{c}\text { Boya } \\
\text { penetrasyonu } \\
\text { yok }\end{array}$ & $\begin{array}{c}\text { Diş ile } \\
\text { restorasyon } \\
\text { arayuzande, } \\
\text { mine-dentin } \\
\text { semınna ulașmus } \\
\text { boya } \\
\text { penetrasyonu }\end{array}$ & $\begin{array}{c}\text { Diş ile } \\
\text { restorasyon } \\
\text { arayuzande, } \\
\text { mine-dentin } \\
\text { sunrimi geçen } \\
\text { ancakk aksiyal } \\
\text { duvara } \\
\text { ulaşmayan boya } \\
\text { penetrasyonu }\end{array}$ & $\begin{array}{c}\text { Diş ile } \\
\text { restorasyon } \\
\text { arayuzzande, } \\
\text { aksiyal duvara } \\
\text { ulasan boya } \\
\text { penetrasyonu }\end{array}$ & $\begin{array}{c}\text { Dentinde } \\
\text { görulen ve } \\
\text { pulpaya kadar } \\
\text { uzanan, lateral } \\
\text { yònlü boya } \\
\text { penetrasyonu } \\
\text { varthẹ̆ı }\end{array}$ \\
\hline $\begin{array}{c}\text { Gingival } \\
\text { kenar }\end{array}$ & $\begin{array}{c}\text { Boya } \\
\text { penetrasyonu } \\
\text { yok }\end{array}$ & $\begin{array}{l}\text { Aksiyal duvara } \\
\text { kadar olan } \\
\text { mesafenin } \\
\text { yarısndan daha } \\
\text { azinı kapsayan } \\
\text { boya } \\
\text { penetrasyonu }\end{array}$ & $\begin{array}{l}\text { Aksiyal duvara } \\
\text { kadar olan } \\
\text { mesafenin } \\
\text { yarısından daha } \\
\text { fazlasın } \\
\text { kapsayan ancak } \\
\text { aksiyal duvara } \\
\text { ulaşmayan boya } \\
\text { penetrasyonu }\end{array}$ & $\begin{array}{c}\text { Aksiyal duvara } \\
\text { ulașan boya } \\
\text { penetrasyonu }\end{array}$ & $\begin{array}{c}\text { Dentinde } \\
\text { görülen ve } \\
\text { pulpaya kadar } \\
\text { uzanan boya } \\
\text { penetrasyonu } \\
\text { yarliğı }\end{array}$ \\
\hline
\end{tabular}

Çalışmada tanımlayıcı veriler sayı, ortalama \pm standart sapma ve medyan (minimum-maksimum) değerleri ile 
gösterildi. Normal dağııım göstermeyen ölçümsel verilerin ikili karşılaştırmalarında Mann-Whitney U testi, üç veya daha fazla sayıdaki grupların karşılaştırmalarında ise Kruskal Wallis testi kullanıldı. Analizler IBM @ SPSS programı 20 sürümü ile gerçekleştirildi. Sonuçlar \%95'lik güven aralığında, anlamlııı $\mathrm{p}<0,05$ düzeyinde değerlendirildi.

\section{BULGULAR}

Çalışmada, incelenen mikrosızıntı değerlerinin dağılımı Tablo 2'de gösterilmiştir.

Tablo 2. Mikrosızıntı değerlerinin dağılımı.

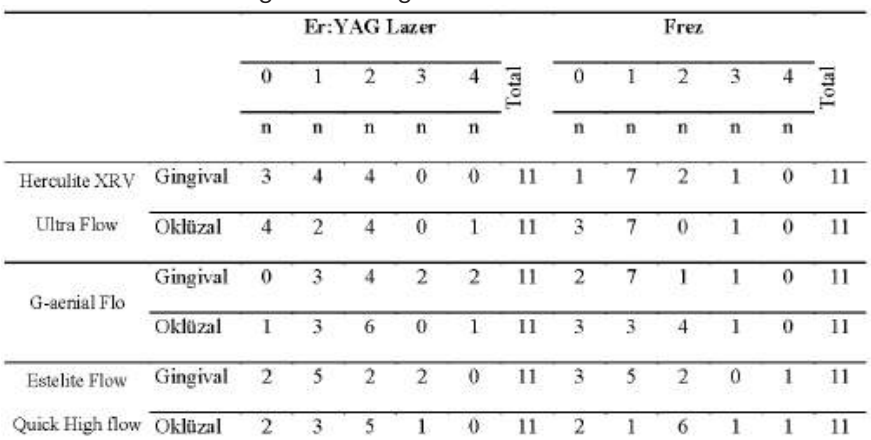

Er:YAG lazer ve frez ile kavite hazırlığı yapılmış örneklerde gingival ve oklüzal yüzeylerde oluşan mikrosızıntı düzeyleri incelenmiştir. Hem frez hem de lazer ile kavite oluşturulan diş örneklerinde, kullanılan akışkan kompozit materyallerinden bağımsız olarak, gingival ve oklüzal yüzeyleri arasındaki mikrosızıntı düzeyleri arasında istatistiksel olarak anlamlı farklılık bulunmamıştır (Tablo 3 ).

Tablo 3. Gingival ve oklüzal yüzeylerde oluşan mikrosızıntının karşılaştırılması

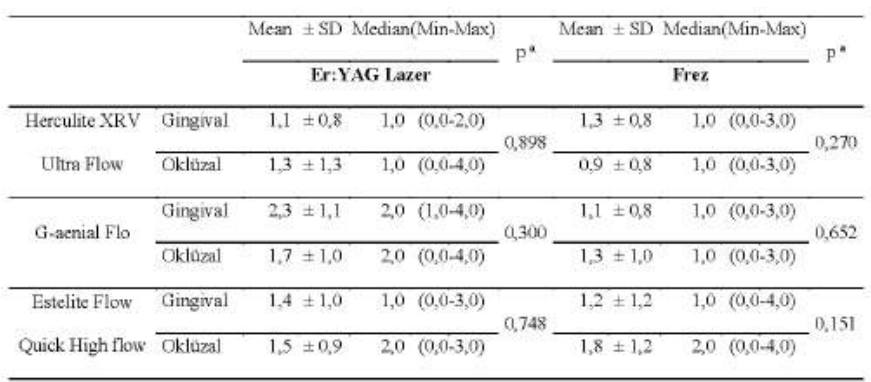

a Mann Whitney U testi

Kullanılan akışkan kompozit materyallerine göre mikrosızıntı düzeyleri incelendiğinde lazer ile kavite oluşturulan örneklerde gruplar arası karşılaştırmalarda anlamlı farklıık saptanmıştır. Herculite XRV Ultra Flow ile restore edilen grupta oluşan mikrosızıntı düzeyi G-aenial Flo ile restore edilen gruba göre anlamlı düzeyde daha düşük bulunurken (p:0,042), diğer gruplardaki mikrosızıntı düzeyleri arasında anlamlı bir fark bulunmamıştır. Frez yöntemi ile kavite oluşturulan örneklerde ise kullanılan akışkan kompozit materyallerinin oluşturdukları mikrosızıntı düzeyleri arasında anlamlı farklılık bulunmamıştır (Tablo 4).
Tablo 4. Lazer ya da frez ile hazırlanan gruplarda akışkan kompozitlerin mikroszıntı düzeylerinin karşılaştırılması.

\begin{tabular}{|c|c|c|c|c|c|c|}
\hline & Mean \pm SD & edian (Min-Max) & \multirow{2}{*}{$\mathrm{p}^{\mathrm{a}}$} & Mean \pm SD & Median (Min-Max) & \multirow{2}{*}{$p^{2}$} \\
\hline & \multicolumn{2}{|c|}{ Er: ÝAG Lazer } & & & Frez & \\
\hline $\begin{array}{c}\text { Herculite XRV } \\
\text { Ultra Flow }\end{array}$ & $1,2 \pm 1,1$ & $1,0 \quad(0,0-4,0)$ & & $1,1 \pm 0,8$ & $1,0 \quad(0,0-3,0)$ & \\
\hline G-aenial Flo & $2,0 \pm 1,1$ & $2,0(0,0-4,0)$ & 0,042 & $1,2 \pm 0,9$ & $1,0 \quad(0,0-3,0)$ & 0,425 \\
\hline Estelite Flow & $1,4 \pm 1,0$ & $1,0 \quad(0,0-3,0)$ & & $1,5 \pm 1,2$ & $1,5 \quad(0,0-4,0)$ & \\
\hline
\end{tabular}

a Kruskal Wallis testi

Kullanılan üç farklı akışkan kompozit ile restore edilen örneklerin gingival ve oklüzal yüzeylerde oluşan mikrosızıntı düzeyi, lazer ve frez kullanımına göre karşılaştırılmıştır. G-aenial Flo grubunda lazerle hazırlanan kavitelerin gingival yüzeylerinde oluşan mikrosızıntı miktarı frezle hazırlanan kavitelerden anlamlı derecede daha fazla bulunmuştur (p:0,013). Diğer gruplarda bu iki farklı yöntem ile oluşturulan kavitelerin gingival ve oklüzal yüzeylerindeki mikrosızıntı düzeyleri arasında istatistiksel olarak anlamlı bir farklııı saptanmamıştır (Tablo 5).

Tablo 5. Akışkan kompozit materyallerin oklüzal ve gingival mikrosızıntı düzeyle rinin farklı kavite hazırlığı yöntemleri açısından karşılaștırılması.

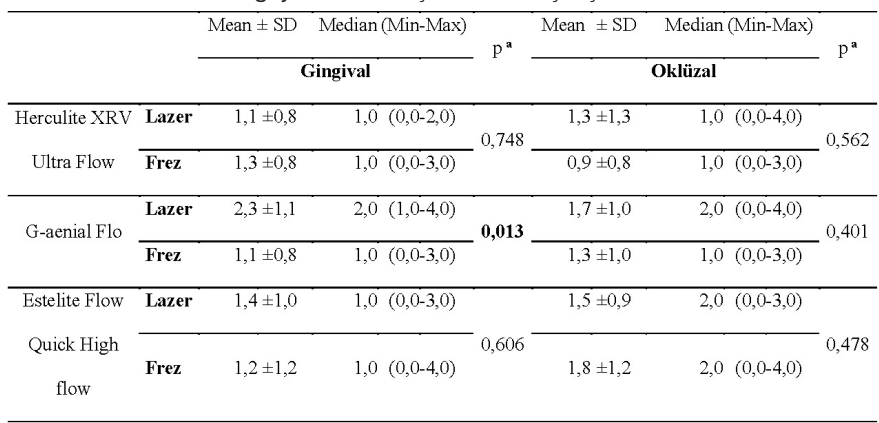

a Mann Whitney U test

\section{TARTIŞMA}

Çalışmada Er:YAG lazer ve geleneksel yöntem olan frez ile kavite hazırığının, akışkan kompozit materyaller ile restore edilen sınıf $\mathrm{V}$ kavitelerdeki mikrosızıntıya olan etkisi incelenmiştir.

Adeziv sistemler ile yapılan restorasyonların uzun dönem klinik başarısının temel unsurlarından birinin, kenar sızdırmazlığının sağlanarak restoratif materyal ile diş sert dokuları arasındaki geçişin engellenmesi olduğu belirtilmiştir. ${ }^{15}$ Adeziv sistemlerin kullanımı ile beraber restorasyonlarda oluşan ve özellikle sınıf $\vee$ kavitelerde daha sık meydana gelen mikrosızıntının önlenebilmesine yönelik birçok çalışma yapılmış ancak kenar sızıntısını tamamen ortadan kaldırabilen herhangi bir restoratif materyal veya teknik geliştirilememiştir. ${ }^{16}$ Ancak yapılan çalışmalarda minenin bizote edilmesi, adeziv sistemlerin kullanımı, kompozitlerin tabakalama tekniği ile uygulanması ve kavite hazırığının lazer ile yapılmasının mikrosızıntıyı azaltabileceği belirtilmiștir. ${ }^{17}$ Bu nedenle bu çalışmada diş dokuları üzerinde termal etkilerinin olmaması ve yüzeyel dokuları aşındırmasındaki avantajları nedeniyle Er:YAG lazerlerin, geleneksel yönteme kıyasla mikrosızıntıyı azaltmadaki etkinliği değerlendirilmiştir. 
Mikrosızıntı oluşumu in vitro ve in vivo olarak değerlendirilebilmektedir. ${ }^{14}$ Boya penetrasyon tekniği, mikrosızıntıların değerlendirildiği in vitro çalışmalarda kullanılan en eski ve en yaygın yöntemdir. Bu amaçla rodamin, metilen mavisi, gümüş nitrat ve bazik fuksin gibi çeşitli boyaların solüsyonları \%0,5-\%10 oranlarında kullanılmaktadır. Metilen mavisi yüksek penetrasyon kabiliyeti, küçük parçacık boyutu, düşük molekül ağırlığı, düşük maliyeti ve kolay kullanımı nedeniyle sıklıkla tercih edilmektedir. ${ }^{14} \mathrm{Bu}$ nedenle çalışmamızda \% 0,5'lik tamponlanmış metilen mavisi solüsyonu kullanılmıştır.

Diş yapısı ve restoratif materyallerdeki ısısal genleşme katsayısı arasındaki farklııklar nedeniyle ağız ortamındaki termal değişiklikler, diş ve restorasyonda farklı derecelerde genleşme ve büzülme sonucu diş-restorasyon ara yüzünde boşluk oluşumuna neden olmakta ve bu durum mikrosızıntıya yol açmaktadır. Ağız ortamındaki ısı değişimlerini taklit etmek için uygulanan yaşlandırma işlemi ile ilgili çalışmalarda 200 ila 1000 döngü arasında değişen yaşlandırma modelleri kullanılmıştır. ${ }^{3,18,19} \mathrm{Bu}$ çalışmada ise Malekafzali ve ark.'nın ${ }^{14}$ çalışmasına benzer olarak örneklere 500 defa yaşlandırma işlemi uygulanmıştır.

Sınıf V kavitelerde restorasyonun apikal sınırı çoğunlukla sementte sonlanmaktadır ve bu alanda oluşan kenar sızıntısı önemli bir klinik sorun olarak ifade edilmektedir. ${ }^{20}$ Sınıf $\mathrm{V}$ kavitelerde lazer ucu mesafesinin iyi ayarlanabilmesi, restoratif materyalin uygulanmasının kolay oluşu ve ışıkla polimerizasyonun rahatlıkla yapılabilmesi gibi nedenlerle bu çalışmada sınıf $\mathrm{V}$ kaviteler tercih edilmiştir. Hazırlanan kavitelerin gingival kenarları sement sınırında, oklüzal kenarları ise mine sınırında sonlandırılarak her iki farklı diş dokusunda oluşan mikrosızıntının ayrı ayrı incelenmesi hedeflenmiştir.

Dentin dokusu ile adeziv sistemlerin bağlanma oranı, yüzeyin ıslanabilirliğine ve buna bağlı oluşan mekanik kilitlenme ile ilişkilidir. Bu nedenle smear tabakasının kaldırılması ve dentinde meydana gelen yüzeyel değişiklikler önem taşımaktadır. ${ }^{21}$ Adeziv sistemlerin dentin dokusuna bağlanmasının dentinin yüksek organik içeriği, farklı mineralizasyon özellikleri ve intratübüler sıvının dış yüzeye doğru hareketi nedeniyle mine dokusuna kıyasla daha zor olduğu belirtilmiştir. ${ }^{18}$ Bazı çalışmalarda, bu bilgiye paralel olarak, sınıf $\mathrm{V}$ kavitelerin dentin/sement sınırında oluşan mikrosızıntının mine sınırına kıyasla daha yüksek olduğunu bildirilmiştir. 7,17,19,21 Ancak bizim çalışmamızda ise Malekafzali ve ark. ${ }^{14}$, Yazici ve ark. ${ }^{22}$, Shafiei ve ark.'nın ${ }^{23}$ çalışmasına benzer olarak oklüzal ve gingival yüzeylerdeki mikrosızıntı düzeylerinin ikili karşılaştırmalarında anlamlı bir farklılık görülmemiştir ( $p>0,05)$.

Akışkan kompozitlerin, sahip oldukları düşük viskozite ve düşük elastik modülü nedeniyle sınıf $\vee$ kavitelerde restorasyon amaçlı kullanımlarının tercih edilebilir olduğu ifade edilmiştir.7 Mekanik avantajlarının yanısıra, klinik uygulamasının kolay ve hızlı olması akışkan kompozitleri diş hekimliğinde kullanım için ideal bir restoratif materyal seçeneği haline getirmektedir. Bu avantajlarının yanında akışkan kompozitlerin, kaviteye enjeksiyonu sırasında viskozitelerinden dolayı sıkışan hava partikülleri oluşturabileceği ve bu partiküllerdeki mikroboşlukların kenar sızıntısına neden olmaması için manipülasyonu esnasında gerekli hassasiyetin gösterilmesi gerektiği vurgulanmıştır.7 Çalışmada kullanılan akışkan kompozit materyalleri karşılaştııılığında frez ile kavite hazırlığı yapılan gruplar arasındaki mikrosızıntı düzeyleri arasında anlamlı farkııık görülmezken; lazer ile kavite hazırlığı yapılan ve Herculite XRV Ultra Flow ile restore edilen grupta oluşan mikrosızıntı düzeyi, G-aenial Flo ile restore edilen gruba göre anlamlı düzeyde daha düşük bulunmuştur (p:0,042). Konu ile ilgili literatürler incelendiğinde, bu çalışmada kullanılan üç farklı akışkan kompozitin mikrosızıntı düzeylerinin karşılaştırıldığı benzer bir çalışma olmadığı görülmüştür.

Lazer ve frez kullanımı sonucu oluşan mikrosızıntı düzeylerinin karşılaştırıldığı çalışmalarda, lazer ile kavite hazırlığı yapılan diş dokularındaki yüzey enerjisinin restorasyonun bağlanmasına katkısını artırması ve smear tabakasının ortadan kaldırıması gibi optimal yüzey özelliklerine sahip olabileceği ve bu durumun daha düşük mikrosızıntı sağladığı ifade edilmektedir. ${ }^{20,21,23}$ Ek olarak lazer ile doku ablasyonundan sonra diş yüzeyinde makro ve mikro pürüzlülüğün oluştuğu ve bunun da optimal yüzey enerjisi ve nem oranı sayesinde hidrofilik adezivlerin diş yüzeyine rahatça bağlanabildiği belirtilmiş; bu nedenle sert doku lazerlerinin frez kullanımına kıyasla daha az mikrosızıntı oluşturacağı ileri sürülmüştür. ${ }^{14}$ Bahrololoomi ve Heydari ${ }^{3}$ ile Tuna ve ark. ${ }^{7}$ ise çalışmalarında Er:YAG lazer ile hazırlanan kavitelerdeki mikrosızıntının frez ile hazırlanan kavitelere kıyasla daha yüksek olduğunu saptamışlardır. Bu bulgu ile lazer ablasyonunun, diş dokusundaki kollajen fibrillerin füzyonuna neden olarak, fibriller arası boşluğu azalttığı ve bu nedenle restoratif materyalin diş yüzeyine olan penetrasyonunu azaltabileceği savunulmuştur. Ek olarak lazer uygulanan yüzeylerdeki fazla mikrosızıntının nedeni olarak yüksek kalsiyum ve fosfor oranının, azalan karbonat kalsiyum oranının ve yüzeyin asit direncinin sebep olabileceği de belirtilmiştir. ${ }^{3}$ Lazer uygulanan dişlerde mikrosızıntının değerlendirildiği çalışmalardaki farklı sonuçlar, kullanılan lazer parametreleri ve seçilen diş örneklerinin farklıı̆ına bağlı olabileceği gibi asitleme aşamasının dahil edilip edilmemesi gibi yöntem farklııkları ile de ilişkili olabilmektedir. ${ }^{14} \mathrm{Bu}$ çalışmada dişler kavite hazırlıkları yapıldıktan sonra asit ile pürüzlendirilmiştir. Lazer ile modifiye edilmiş dentin tabakasında kollajen fibriller lazer ISISI nedeniyle birbirleriyle birleşmekte ve böylece fibriller arası boşluk kapanmaktadır. Dolayısıyla uygulanan adeziv reçine çoğunlukla lazer ile modifiye edilen bu dentin tabakası ile sınırlı kalmakta, daha derine inmemektedir. ${ }^{14}$ 
Bununla birlikte lazerle hazırlanan yüzeylere asit uygulanmasının ıslanabilirliği ve pürüzlülüğü arttıracağı, kimyasal ve morfolojik değişikliklere neden olarak bağlanmayı olumlu etkileyebileceği bildirilmiştir. Diğer yandan frezle hazırlanan yüzeylerde bağlanmayı olumsuz etkileyen smear tabakası oluşmaktadır. Frez uygulanan bu yüzeylerde asit uygulaması ise dentin tübüllerini genişletmekte, demineralize etmekte ve hibrid tabakanın oluşumuna yardımcı olmaktadır. ${ }^{20,24}$ Bu nedenle lazer ve asit uygulaması sonucu oluşturulan yüzey ile frez ve asit uygulaması sonucu oluşturan yüzeydeki topografik değişikliklerin benzer olacağı ve böylece oluşan mikrosızıntı düzeyleri arasında anlamlı farklılık olmayabileceği belirtilmiştir. ${ }^{14}$ Bizim çalışmamızda da yapılan çalışmalara benzer olarak kavite hazırlığında kullanılan lazer ve frez yöntemlerinin, gruplar arasında oklüzal ve gingival yüzeylerdeki mikrosızıntı düzeylerinde anlamlı bir farklılık oluşturmadığı görülmüştür (p>0.05). ${ }^{8,17,25}$

Sonuç olarak, sınıf V kavitelerdeki kompozit restorasyonlar için kavite hazırlama yöntemlerinin hiçbiri mikrosızıntıyı tamamen ortadan kaldıramamıştır. Lazer ile kavite hazırlığı yapılan gruplarda akışkan kompozitlerin mikrosızıntı düzeyleri arasında anlamlı farklar gözlenirken, frez ile hazırlanan gruplarda akışkan kompozitler farklılık göstermemiştir. Gerek frez gerek Er:YAG lazer kullanılan gruplarda, oklüzal ve gingival yüzeylerdeki mikrosızıntı düzeyleri anlamlı bir farklılık göstermemiştir.

\section{KAYNAKLAR}

1. Soni HK, Sharma A, Sood PB. A comparative clinical study of various methods of caries removal in children. Eur Arch Paediatr Dent 2014; 16: 19-26.

2. Juntavee A, Juntavee N, Peerapattana J, Nualkaew N, Sutthisawat S. Comparison of Marginal Microleakage of Glass Ionomer Restorations in Primary Molars Prepared by Chemomechanical Caries Removal (CMCR), Erbium: Yttrium Aluminum-Garnet (Er:YAG) Laser and Atraumatic Restorative Technique (ART). Int J Clin Pediatr Dent 2013; 6: 75-79.

3. Bahrololoomi Z, Heydari E. Assessment of Tooth Preparation via Er:YAG Laser and Bur on Microleakage of Dentin Adhesives. J Dent (Tehran) 2014; 11: 172-179.

4. Van As G. Erbium lasers in dentistry. Dent Clin North Am 2004; 48: 1017-1059.

5. Bader C, Krejci I. Indications and limitations of Er:YAG laser applications in dentistry. Am J Dent 2006; 19: 178186.

6. Verma S, Chaudhari $P$, Maheshwari S, Singh R. Laser in dentistry: An innovative tool in modern dental practice. Natl J Maxillofac Surg 2012; 3: 124-132.

7. Tuna EB, Ozel E, Kasimoglu Y, Firatli E. Investigation of the Er: YAG laser and diamond bur cavity preparation on the marginal microleakage of Class $V$ cavities restored with different flowable composites. Microsc Res Tech 2017; 80: 530-536.

8. Li T, Zhang X, Shi H, Ma Z, Lv B, et. al. Er:YAG laser application in caries removal and cavity preparation in children: a meta-analysis. Lasers Med Sci 2019; 34: 273-280

9. Guven Y, Aktoren O. Shear bond strength and ultrastructural interface analysis of different adhesive systems to Er:YAG laser-prepared dentin. Lasers Med Sci 2015; 30: 769-778.

10. Nematollahi $H$, Bagherian A, Ghazvini $K$, Esmaily $H$, Mina AM. Microbial microleakage assessment of class $\mathrm{V}$ cavities restored with different materials and techniques: A laboratory study. Dent Res J (Isfahan) 2017; 14: 344350.

11. Bonilla ED, Stevenson RG, Caputo AA, White SN. Microleakage resistance of minimally invasive Class I flowable composite restorations. Oper Dent 2012; 37: 290-298. 12. Ozel E, Soyman M. Effect of fiber nets, application techniques and flowable composites on microleakage and the effect of fiber nets on polymerization shrinkage in class II MOD cavities. Oper Dent 2009; 34: 174-180.

13. Awliya WY, El-Sahn AM. Leakage pathway of Class V cavities restored with different flowable resin composite restorations. Oper Dent 2008; 33: 31-36.

14. Malekafzali B, Asnaashari $M$, Javadi F. Comparison of marginal microleakage of flowable composite restorations in primary canine teeth prepared with high-speed diamond bur, ER:YAG laser and ER,CR:YSGG laser. Laser Ther 2017; 26: 195-202.

15. Yılmaz EK, Çelik EU, Savaş S, Bölükbaşı B. Sınıf V Kavitelerde Kendinden Bağlanabilen Akışkan Kompozitlerin Mikrosızıntılarının Karşılaştırılması. Cumhur Dent J 2015; 18: 116-127.

16. Jordehi A, Shahabi $M$, Akbari A. Comparison of self-Adhering flowable composite microleakage with several types of bonding agent in class $v$ cavity restoration. Dent Res J (Isfahan) 2019; 16: 257-263.

17. Ghandehari M, Mighani G, Shahabi S, Chiniforush N, Shirmohammadi Z. Comparison of Microleakage of Glass Ionomer Restoration in Primary Teeth Prepared by Er: YAG Laser and the Conventional Method. J Dent (Tehran) 2012; 9: 215-220.

18. Trelles KT, Arnabat J, España-Tost T. Microleakage in class $\mathrm{V}$ cavities with self-etching adhesive system and conventional rotatory or laser Er, Cr:YSGG. Laser Ther 2012; 21: 255-268.

19. Baygin O, Korkmaz FM, Arslan I. Effects of different types of adhesive systems on the microleakage of compomer restorations in class $\mathrm{V}$ cavities prepared by Er,Ccr:YSGG laser in primary teeth. Dent Mater J 2012; 31: 206-214. 20. Shahabi S, Ebrahimpour L, Walsh LJ. Microleakage of composite resin restorations in cervical cavities prepared by Er,Cr:YSGG laser radiation. Aust Dent J 2008; 53: 172- 
175.

21. Fattah $T$, Kazemi $H$, Fekrazad $R$, Assadian $H$, Kalhori KAM. Er,Cr:YSGG laser influence on microleakage of class v composite resin restorations. Lasers Med Sci 2013; 28 : 1257-1262.

22. Yazici AR, Yıldırım Z, Antonson SA, Kilinc E, Koch $D$, Antonson DE, et al. Comparison of the Er,Cr:YSGG laser with a chemical vapour deposition bur and conventional techniques for cavity preparation: A microleakage study. Lasers Med Sci 2012; 37: 23-29.

23. Shafiei $F$, Memarpour M. Effect of acid etching on long-term microleakage of nano ionomer restorations in bur- and laser-prepared cavities in primary teeth. $\mathrm{J}$ Dent Child 2015; 82: 3-9.

24. Rossi RR, Aranha AC, Eduardo CDP, Ferreira LS, Navarro $\mathrm{R}$, et. al. Microleakage of glass ionomer restoration in cavities prepared by Er,Cr:YSGG laser irradiation in primary teeth. J Dent Child 2008; 75: 151-157.

25. Korkmaz FM, Baygin O, Tuzuner T, Bagis B, Arslan I. The effect of an erbium, chromium: Yttrium-scandium-gallium-garnet laser on the microleakage and bond strength of silorane and micro-hybrid composite restorations. Eur $\mathrm{J}$ Dent 2013; 7: S033-S040. 